\title{
The behavioral functions of stimuli signaling transitions across rich and lean schedules of reinforcement
}

Jessica B. Long

West Virginia University

Follow this and additional works at: https://researchrepository.wvu.edu/etd

\section{Recommended Citation}

Long, Jessica B., "The behavioral functions of stimuli signaling transitions across rich and lean schedules of reinforcement" (2005). Graduate Theses, Dissertations, and Problem Reports. 2306.

https://researchrepository.wvu.edu/etd/2306

This Thesis is protected by copyright and/or related rights. It has been brought to you by the The Research Repository @ WVU with permission from the rights-holder(s). You are free to use this Thesis in any way that is permitted by the copyright and related rights legislation that applies to your use. For other uses you must obtain permission from the rights-holder(s) directly, unless additional rights are indicated by a Creative Commons license in the record and/ or on the work itself. This Thesis has been accepted for inclusion in WVU Graduate Theses, Dissertations, and Problem Reports collection by an authorized administrator of The Research Repository @ WVU. For more information, please contact researchrepository@mail.wvu.edu. 
The Behavioral Functions of Stimuli Signaling Transitions across Rich and Lean

\author{
Schedules of Reinforcement
}

Jessica B. Long

Thesis submitted to the Eberly College of Arts and Sciences at West Virginia University in partial fulfillment of the requirements for the degree of

Master of Science

in

Psychology

\author{
Michael Perone, Ph.D., Chair \\ Karen G. Anderson, Ph.D. \\ Julie Hicks Patrick, Ph.D. \\ Department of Psychology
}

Morgantown, West Virginia

2005

Keywords: conditioned reinforcement, post-reinforcement pause, observing procedure, conditioned punisher, pigeon 


\begin{abstract}
The Behavioral Functions of Stimuli Signaling Transitions across Rich and Lean Schedules of Reinforcement

Jessica B. Long

The present experiment was designed to assess whether stimuli correlated with rich and lean fixed-ratio schedule components would function as conditioned reinforcers and conditioned punishers, respectively. Pigeons responded on a mixed schedule with fixed-ratio components leading to large or small food reinforcers. Pecks on either of two observing keys converted the mixed schedule to a multiple schedule by turning on a color associated with the current component. The stimulus consequences of the observing responses were manipulated across conditions. Pecks on one observing key produced the rich stimulus and the lean stimulus whereas pecks on the other observing key produced only the rich or the lean stimulus. The stimulus correlated with the large reinforcer functioned as a conditioned reinforcer — it maintained observing behavior — whereas the stimulus correlated with the small reinforcer did not. There was no evidence that the stimulus correlated with the small reinforcer functioned as a
\end{abstract} conditioned punisher. 


\section{Acknowledgements}

I thank Mike Perone, Karen Anderson, and Julie Patrick for their helpful suggestions as members of my thesis committee. I am particularly thankful to Mike Perone for serving as committee chair and for his direction and assistance throughout this project. He continues to shape my behavior as an individual and a scientist, and I am indebted to him for his influence.

I thank Harold Lobo for graciously allowing me the use of his data-analysis program during the preliminary phases of this project. I also thank Lara Johnson, Jeff Everly, and Anne Foreman for their assistance conducting daily sessions. I am particularly grateful to Jeff Everly for his assistance with programming and for the general help he has given me during my first few years in graduate school. Finally, I thank my family for their encouragement and support. 


\section{Table of Contents}

Acknowledgements. 


\section{List of Figures}

Figure 1. Pausing on the center key during preliminary training as a function of the past component and the stimulus correlated with the present component.

Figure 2. Probabilities of pecking the left and right observing keys in each condition.......20

Figure 3. Percentage of all ratios birds completed in the presence of the lean, mixed, and rich

stimuli, as organized by the past component.

Figure 4. Latencies to peck the left and right observing keys as a function of the past component for all experimental conditions .24

Figure 5. Probabilities of pecking the observing keys arranged according to the probability that an observing response will produce the lean stimulus $(0, .5,1.0)$.

Figure 6. Latencies of pecking the observing keys according to the probability that an observing

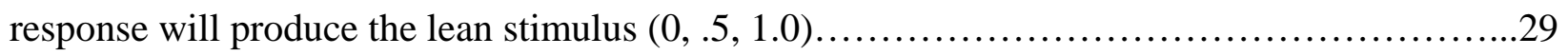
Figure 7. Pausing on the food key as a function of the past component and the stimulus correlated with the current component. Data are plotted for each experimental condition. .30 


\section{List of Tables}

Table 1. Consequences of pecking the left and right observing keys in each condition. The number of sessions completed in each condition for each bird are listed........................16

Table 2. Order of experimental conditions for all birds......................................17

Table 3. Conditional probabilities that an observing response would produce the lean stimulus. For each experimental condition, probabilities are organized according to the past component

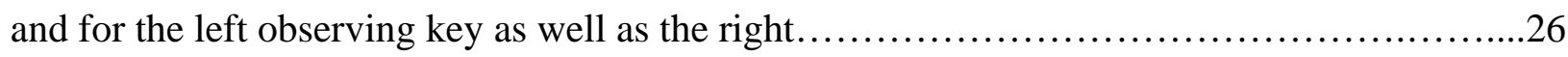




\section{Introduction}

Research has shown that operant behavior is disrupted when the conditions of reinforcement shift discriminably from those that are relatively rich, or favorable, to those that are relatively lean, or unfavorable. A study by Perone and Courtney (1992) provides an example. They studied pauses in the key pecking of pigeons in the transitions between fixedratio (FR) schedules leading to large and small amounts of food reinforcement (6-s vs. 2-s access to mixed grain). When these schedule components were accompanied by distinctive key colors (i.e., a multiple schedule was in effect), pauses were long in the transition from the rich component (with a large reinforcer) to the lean component (with a small reinforcer). By comparison, pauses were brief in the other transitions: from a rich component to another rich component, from lean to lean, and from lean to rich. When the schedules were unsignaled - that is, when the key color did not change in concert with the component in effect (in technical terms, a mixed schedule) - the extended pausing in the rich-to-lean transition was no longer observed. Pausing

The extended pausing that occurs during the rich-to-lean transition is a general phenomenon, having been replicated in studies that vary in terms of both the method by which favorability is manipulated and the species of the subjects. Perhaps the most comprehensive demonstration was reported by Courtney (1994), who conducted a series of experiments with pigeons on the effects of reinforcer magnitude (duration of access to grain), ratio size, and fixedinterval (FI) duration.

Throughout Courtney’s (1994) experiments, sessions were arranged such that approximately half of the components were rich and the rest were lean. Components alternated irregularly with the transitions divided equally among the four possible types: lean-to-lean, 
lean-to-rich, rich-to-lean, and rich-to-rich. For each session, the exact order of the transitions was determined by one of 40 possible sequences with the following restrictions: a) each transition type occurred five times within a session and b) no more than five components of the same type could occur in succession.

In one experiment, a multiple FR FR schedule was in effect. Components were identical in their ratio requirements (both FR 60 for one bird, FR 80 for a second bird, and FR 90 for a third) but differed in reinforcer magnitude. In the lean component, completion of the ratio requirement resulted in 1-s or 1.5-s access to grain, depending on the bird. Completion of the ratio requirement in the rich component produced 7-s or 6.5-s access to grain. Pausing was extended in the rich-to-lean transition but brief in all other transition types. Similar results were obtained when the effects of reinforcer magnitude were studied using multiple FI FI schedules.

In another experiment, Courtney (1994) examined the effects of ratio size using multiple FR FR schedules. In both components, completion of the ratio requirement led to 4-s access to grain. Components differed in ratio size. For all birds, an FR 10 was in effect in the rich component. In the lean component, however, the ratio requirement was higher and varied across birds (FR 30, FR 70, and FR 110). Leaner FRs produced longer pauses, but pauses were longest in the lean FRs preceded by a rich component. By contrast, pausing in the other transition types was short.

A similar effect was obtained when multiple FI FI schedules were used and interval length, as opposed to ratio size, was manipulated. Both components ended in 4-s access to grain. In the rich component, an FI-10 s schedule was programmed. In the lean component, the FI was $70 \mathrm{~s}$ or $80 \mathrm{~s}$. Consistent with previous research, pausing was longest during the rich-to-lean transition. Overall, Courtney’s (1994) results demonstrate that regardless of how favorability 
was defined, pauses were longest in the transition between a rich component (with a large reinforcer, short ratio, or short interval) and a lean component.

Wade-Galuska, Perone, and Wirth (2005) manipulated favorability in terms of the force required of rats to press a lever to produce single food pellets. Across conditions, a multiple FR-30 FR-30 schedule was in effect. Each component was associated with a particular lever and the amount of force required to press each lever differed across components. During the baseline condition, the force requirement of both levers was equal (0.25N). Across subsequent conditions, one lever's force requirement was increased in steps of $0.15 \mathrm{~N}$ while the other's remained constant. When the high-force requirement was increased to $0.40 \mathrm{~N}$, pausing was longest in the rich-to-lean transition, that is, in the transition from the low-force component to the high-force component. This effect was intensified when the high-force requirement later was increased to $0.55 \mathrm{~N}$. For some rats, the high-force requirement was increased further to $0.70 \mathrm{~N}$ and 0.85N. During these conditions, pauses were longest in the rich-to-lean transition, albeit to a lesser extent than in previous conditions.

Bejarno, Williams, and Perone (2003) conducted their experiment with a man with mental retardation. Each completion of a match-to-sample discrimination trial constituted one response toward the completion of an FR schedule. In the lean component, completing an FR-60 schedule earned a 1-cent reinforcer. In the rich component, completing an FR-10 earned 25 cents. Rich-to-lean transitions produced the longest pauses.

\section{Escape}

In light of these and other findings, Perone (2003) suggested that the pausing may function as a form of escape. Azrin (1961) proposed that schedules of food reinforcement can have aversive functions, and other research has shown that animals will escape from FR, (Appel, 
1963; Ator, 1980), FI (Brown \& Flory, 1972; Cohen \& Campagnoni, 1989) and progressive-ratio schedules of positive reinforcement (Dardano, 1973). In these studies, escape, like pausing, was more likely to occur immediately after a reinforcer.

Direct evidence favoring the suggestion that pausing functions as a form of escape comes from studies by Metzger (1990) and Carlin (1997). Using a procedure developed by Azrin (1961), Metzger (1990) investigated key pecking in pigeons on a series of mixed and multiple FR FR schedules where responses in the two components produced either a small reinforcer (lean component) or a large reinforcer (rich component). At the start of some ratios, an escape key was made available. If the birds pecked the escape key before pecking the food key, a timeout was initiated during which the houselight was turned off, the food key was darkened and inoperative, and the escape key was dimmed. After at least $1 \mathrm{~s}$ had passed, a peck on the escape key ended the timeout, the food key and houselight were relit, and the escape key was darkened and inoperative.

When a mixed schedule was in effect and no stimuli signaled the current component, pausing was controlled only by the past component; the longest pauses occurred after a large reinforcer. Escape was rare in all four transition types. When a multiple schedule was programmed, however, pausing was longest and escape occurred most often during the rich-tolean transition. Birds also spent a greater percentage of the session in timeout when the multiple schedule was programmed compared to when a mixed schedule was arranged.

Carlin (1997) extended Metzger’s findings by examining pausing and escape when pigeons were trained on a multiple FI FI schedule in which more extreme differences were arranged between the large (15-s access to grain) and small (1-s) reinforcers. At the start of some intervals, an escape key was available. If the escape key was pecked first, a timeout began 
during which the houselight was turned off, the food key was darkened and inoperative, and the escape key dimmed. The FI timer continued to elapse throughout the timeout. After a minimum of $1 \mathrm{~s}$, a second peck on the escape key ended the timeout; the houselight and food key were relit and the escape key was darkened and inoperative. Pausing was longer, escape occurred more often, and a greater percentage of the session was spent in timeout during the rich-to-lean transition. Pausing, the number of escapes, and the time spent in timeout systematically increased as the interval duration increased from $60 \mathrm{~s}$ to $960 \mathrm{~s}$ across sessions.

Taken together, the results of Courtney (1994), Wade-Galuska, Perone, and Wirth (2005), Bejarno, Williams, and Perone (2003), Metzger (1990), and Carlin (1997) indicate that regardless of whether favorability is defined in terms of ratio size, interval duration, force requirement, or reinforcer magnitude, and regardless of the species used, behavior was disrupted, specifically pausing was extended, escape occurred more often, and a greater percentage of the session time was spent in time out, during the rich-to-lean transition. Note that the disruptive effects of the rich-to-lean transition occurred only when there were stimuli correlated with the current component. When the rich-to-lean transition was not discriminable, as was the case when a mixed schedule was used, pausing, escape, and session time spent in timeout did not differ across the four transition types.

Given that the disruptive effects of the rich-to-lean transition were limited to conditions in which stimuli signaled the components, of interest are the behavioral functions of the stimulus correlated with the lean component, hereafter the lean stimulus. The functions of the lean stimulus, however, cannot be clearly assessed from the previous findings. In Metzger’s procedure, escape responses removed the discriminative stimulus from the food key, and they deactivated the key itself. Because the offset of the lean stimulus was confounded with the 
deactivation of the instrumental response, the behavioral functions of the lean stimulus per se are unclear. Therefore, another approach is needed.

\section{Observing}

The behavioral function of a discriminative stimulus may be identified by way of an observing procedure (Wyckoff, 1952). In a typical instance of this procedure, a pigeon pecks a key for food on a mixed schedule with two randomly alternating components. By pecking another key - the observing key - the pigeon turns on stimuli that signal the component in effect on the food key (i.e., observing responses convert a mixed schedule to a multiple schedule).

Mulvaney, Dinsmoor, Jwaideh, and Hughes (1974) used an observing procedure to examine the functions of the rich and lean stimuli, namely stimuli correlated with variableinterval (VI) and extinction (EXT) schedules of food reinforcement. Two observing keys were available at the same time. Pecks on one observing key occasionally produced the stimulus correlated with the VI component, hereafter the rich stimulus, if the VI component was in effect on the food key. Pecks on the other observing key could produce either the rich stimulus (during the VI component) or the lean stimulus (during the EXT component). Response rates were lower on the key that produced both stimuli, indicating that the lean stimulus suppressed observing. Mulvaney et al. concluded that the lean stimulus was a conditioned punisher. The rich stimulus functioned as a conditioned reinforcer as responding was maintained on the observing key that produced only this stimulus.

Jwaideh and Mulvaney (1976) used an observing procedure to assess the function of the lean stimulus when it signaled the leaner of two reinforcement schedules. Pecks on a center key were reinforced according to a mixed VI-30s VI-120s schedule. Responses on the side (observing) keys converted the mixed schedule to a multiple schedule for $30 \mathrm{~s}$. At the 
experiment's outset, responses on either observing key could produce either the rich stimulus (correlated with a VI-30s) or the lean stimulus (correlated with a VI-120s), depending on the current component. Across subsequent conditions, the consequences of the observing keys were manipulated such that one observing key could produce only the rich stimulus or the lean stimulus and the other key could produce both the rich and the lean stimulus. When one key produced only the rich stimulus and the other key produced both stimuli, response rates were higher on the key that produced only the rich stimulus. When one key produced only the lean stimulus and the other key produced both stimuli, response rates were higher on the key that produced both stimuli. Responding was not maintained on the key that produced only the lean stimulus. Jwaideh and Mulvaney concluded that the rich stimulus functioned as a conditioned reinforcer because this stimulus maintained observing and the lean stimulus functioned as a conditioned punisher because it suppressed observing.

\section{Delay-Reduction Hypothesis}

Both Mulvaney et al.’s (1974) and Jwaideh and Mulvaney’s (1976) results are consistent with Pavlovian theories of conditioned reinforcement. One Pavlovian theory in particular, the delay-reduction hypothesis (Fantino, 1977), has received substantial empirical support (Case \& Fantino, 1981; O’Daly, Meyer, \& Fantino, 2005; Preston \& Fantino, 1991; Williams \& Fantino, 1994). According to the delay-reduction hypothesis, the reinforcing strength of a stimulus is determined by the interval between the onset of the stimulus and the onset of primary reinforcement. This interval, however, must be considered relative to how remote primary reinforcement had been prior to the onset of the stimulus. Hence, the delay-reduction hypothesis predicts that a stimulus correlated with a relative reduction in time to primary reinforcement should function as a conditioned reinforcer (Fantino, 1977). The greater the improvement is, in 
terms of relative reduction in the delay to reinforcement, the greater the reinforcing strength of the stimulus. Given the predictions regarding the strength of a stimulus as a conditioned reinforcer, it may follow that a stimulus correlated with a relative increase in the delay to reinforcement should function as a conditioned punisher (Perone \& Kaminski, 1992). Empirical support for the latter prediction comes from studies by Auge (1974), Blanchard (1975), Case and Fantino (1981), Jwaideh and Mulvaney (1976), Kendall and Gibson (1965), and Mulvaney et al. (1974).

The results of Mulvaney et al. (1974) are consistent with the delay-reduction hypothesis. In their experiment, the rich stimulus signaled a VI schedule whereas the lean stimulus signaled an EXT schedule. The two schedule components alternated randomly every 30 s on average such that when no observing responses were made and the mixed stimulus was present, the average delay to reinforcement was 60 s. In the presence of the rich stimulus, the average delay to reinforcement was $30 \mathrm{~s}$. Hence, the rich stimulus was correlated with a reduction in the delay to reinforcement relative to when the mixed stimulus was present. Consistent with the delayreduction hypothesis, the rich stimulus functioned as conditioned reinforcer as it maintained observing. The lean stimulus signaled that a reinforcer would not be delivered, and therefore, was correlated with an increased delay to reinforcement relative to when the mixed stimulus was present. The lean stimulus suppressed observing, consistent with the delay-reduction hypothesis' prediction that a stimulus correlated with a relative increase in the delay to reinforcement should function as a conditioned punisher.

The findings of Jwaideh and Mulvaney (1976) also may be accounted for by the delayreduction hypothesis. In their experiment, the rich stimulus signaled a VI-30s schedule and the lean stimulus signaled a VI-120s schedule. In the absence of the rich or lean stimulus, when the 
mixed stimulus was present, the average delay to reinforcement was 75 s. According to the delay-reduction hypothesis, the rich stimulus should have functioned as a conditioned reinforcer because it was correlated with a relative reduction in the delay to reinforcement (30 s compared to $75 \mathrm{~s}$ ). Likewise, the lean stimulus should have functioned as a conditioned punisher by way of its correlation with a relative increase in the delay to reinforcement (120 s compared versus 75 s). Both of these predictions were supported; the rich stimulus maintained observing and the lean stimulus suppressed it.

\section{Statement of the Problem}

The present research focused on the nature of the lean stimulus. Previous research (Bejarno, Williams, \& Perone, 2003; Carlin, 1997; Courtney, 1994; Metzger, 1990; Perone \& Courtney, 1992; Wade-Galuska, Perone, \& Wirth, 2005) has shown that when there are discriminable shifts between rich and lean conditions of reinforcement, behavior is disrupted. The fact that pausing is extended and, if given the opportunity, animals will escape during discriminable rich-to-lean transitions suggests the possibility that the stimulus correlated with the lean component is aversive at least when preceded by a rich component. But the pausing and escape data do not demand such an interpretation. It is possible that it is the lean schedule component that is aversive, and that the stimulus serves only to demarcate the component and allow it to be discriminated. Other evidence is needed to see whether the lean stimulus is aversive per se.

The present study combined elements of the concurrent observing procedure of Mulvaney et al. (1974) with the procedures used by Perone and Courtney (1992) to assess the behavioral functions of stimuli defining the transitions between relatively rich and lean schedule 
components. Of particular interest was how variations in the local environment influenced the behavioral functions of the stimuli.

In the critical conditions, pigeons' pecks on a center key were reinforced according to a mixed FR-100 FR-100 schedule. Completion of the ratio requirement produced either a small (1-s access to grain) or a large (6- or 7-s access) reinforcer, depending on whether the lean or rich component was in effect. At the start of some ratios, the left or right observing key was activated. Pecks on an active observing key converted the mixed schedule to a multiple schedule by replacing the mixed stimulus with a stimulus correlated with the current component. The consequences of the two observing keys were then manipulated across conditions. In the baseline condition, pecks on either key could produce the rich stimulus or the lean stimulus. In subsequent conditions, one key could produce both stimuli whereas the other observing key could produce only the rich or only the lean stimulus. The behavioral functions of the rich and lean stimuli were assessed by comparing the strength of pecking the observing keys across conditions, with strength defined in terms of probability of, and latencies to, peck. If the rich stimulus functions as a conditioned reinforcer, observing responses that produce only the rich stimulus should be strongly maintained across all conditions of the experiment. If the lean stimulus functions as a conditioned punisher, observing responses that produce the lean stimulus as well as the rich stimulus should be suppressed across all experimental conditions. When observing responses produce only the lean stimulus, observing should not be maintained.

Method

\section{Subjects}

Four male White Carneau pigeons, all with experience on a variety of schedules, were maintained at $80 \%( \pm 2 \%$ ) of their free-feeding weights by grain deliveries during the 
experimental sessions and, if necessary, by supplemental feedings at least 30 min afterwards. Water and health grit were freely available in the home cage, which was kept in a temperaturecontrolled room with a 12:12 hr light/dark cycle.

\section{Apparatus}

Four standard sound-attenuating chambers were used. Each chamber measured $37 \mathrm{~cm}$ high, $30 \mathrm{~cm}$ wide, and $32 \mathrm{~cm}$ deep. General illumination was provided by a 28-v houselight (No. 1819) located behind a translucent screen in the lower left corner of the front panel. Three response keys, about $2 \mathrm{~cm}$ in diameter, were arranged in a row on the front panel $24 \mathrm{~cm}$ from the floor and $9 \mathrm{~cm}$ apart, center to center. Keys were illuminated from behind by 28-v bulbs (No. 1829) covered with colored caps. Food reinforcers consisted of access to mixed grain through an illuminated (No. 1819 bulb) 5-cm x 6-cm rectangular aperture located approximately $11 \mathrm{~cm}$ below the center key. Noise from a ventilation fan on the side of the chamber masked extraneous sounds. Experimental events were controlled and recorded using microcomputers connected to the chambers by a commercial interface.

\section{General Procedure}

Sessions were conducted 6 days per week at approximately the same time each day. Before the session started, the pigeon stood in the darkened chamber for $5 \mathrm{~min}$. This pre-session delay allowed the pigeon to recover from any disruptive effects of handling. The session began with the onset of the houselight and illumination of any operational pecking keys. Sessions ended after 41 food reinforcers were delivered or after a maximum of $2 \mathrm{hr}$. During a reinforcer presentation, the houselight and keylights were extinguished and the food aperture was lit. If the pigeon pecked a darkened key during the first $1 \mathrm{~s}$ of the reinforcement cycle, the clock 
controlling the duration of the grain presentation was reset until pecking ceased for $1 \mathrm{~s}$. This ensured that the pigeon did not peck through the reinforcement cycle.

Throughout the experiment, food reinforcers were programmed on a compound schedule with two components. Both components had identical FRs but different reinforcer magnitudes. In the lean component, the reinforcer was 1-s access to grain. In the rich component, the reinforcer was either 6-s access (Birds $6689 \& 4266)$ or 7-s access (6693 \& 6994). (The magnitude of the reinforcer in the rich component was adjusted to help keep the birds' weights within acceptable limits.) In some cases, the components were accompanied by distinctive key colors, that is, a multiple FR FR schedule was programmed. The color that accompanied the lean component was blue (Birds 6693 \& 6994) or green (6689 \& 4266). The color that accompanied the rich component was green (Birds 6693 \& 6994) or blue (6689 \& 4266). In other cases, a mixed FR FR schedule was programmed: The lean and rich stimuli were withheld and the food key was lit white (hereafter, mixed stimulus) regardless of the schedule component in effect.

Components alternated in an irregular fashion as described by Perone and Courtney (1992), so that the transitions between the components were divided equally among the four possible types: from a lean component to another lean component (lean-to-lean), from a lean component to a rich component (lean-to-rich), from a rich component to a lean component (richto-lean), and from a rich component to another rich component (rich-to-rich). Each type of transition occurred 10 times per session. The exact order of the transitions was determined by 40 sequences developed by Perone and Courtney (1992). The 40 sequences were in two sets, with 20 in each. One set included sequences with 20 lean components and 21 rich components, with the first being a rich one. Sequences in the other set had 21 lean components and 20 rich 
components, with the first being a lean one. The sequences were arranged so that no more than four lean or four rich components occurred in succession. For each pair of sessions, the sequence for the first session was randomly selected from either set and the sequence for the second session was randomly selected from the other set. If the same sequence was selected for a second consecutive session, however, the selection process was repeated.

\section{Preliminary Training}

Preliminary training was divided into two phases. The first phase was designed to establish responding on a multiple schedule with the lean and the rich components described above. The goal of the second phase was to establish responding on all three keys. This was needed because, in the experiment proper, two keys were activated simultaneously. A history of responding on all three keys would foster contact with the full range of experimental contingencies.

Phase 1. The first phase started with a multiple schedule in which both the rich component (6- or 7-s reinforcer) and the lean component (1-s reinforcer) had an FR-40 schedule. Thereafter, the ratio requirement in each component was increased from FR 40 to 100 in steps of 10. Each FR value was in effect for two sessions. The active response key was rotated across sessions (from left to center to right, in that order) until the FR requirement reached 100. At that point, the multiple schedule was confined to the center key (hereafter, the food key).

The first phase of preliminary training was terminated when pausing on the multiple FR100 FR-100 schedule stabilized in each of the four transitions. Beginning with the $16^{\text {th }}$ session, the median pause duration in each transition was calculated over a moving window of the most recent 10 sessions. The first median was based on the pauses obtained in sessions 7 through 16; the second median on sessions 8 through 17; and so on. When a block of five consecutive 
medians showed no increasing or decreasing trend, the measure was judged stable. When the pause durations in each of the four transition types met the stability criteria simultaneously, the first phase of preliminary training was ended, and the second phase began. This required 48, 36, 49, and 52 sessions for Birds 6693, 6994, 6689, and 4266, respectively.

Phase 2. During the second phase of preliminary training, the observing response was introduced. To facilitate the acquisition of observing, responses could produce only the rich stimulus. A mixed FR-100 FR-100 schedule was programmed on the food key and, in the rich components, one of the two side keys (hereafter, observing keys) was activated. Like the food key, the active observing key was lit with the mixed stimulus. When a rich component was in effect, a single peck on the active observing key replaced the mixed stimulus on the food key with the rich stimulus, and the observing key was darkened and deactivated. The rich stimulus remained on until the bird completed the FR requirement. This procedure allowed for a maximum of 10 observing responses on the left observing key and 10 on the right. The second phase of preliminary training was terminated when the number of left and right observing responses each was eight or more. Phase 2 lasted for three sessions for Birds 6693 and 6994 and six sessions for Birds 6689 and 4266.

\section{Experimental Conditions}

In the experimental conditions, a mixed FR-100 FR-100 schedule was programmed on the food key and, in some components, one or the other observing key was activated and illuminated with the same mixed stimulus as the food key. In contrast with the preliminary training, an observing key could be activated during lean components as well as rich ones and, therefore, observing responses could produce the lean stimulus as well as the rich stimulus. A single peck of an active observing key replaced the mixed stimulus on the food key with either 
the lean stimulus (during a lean component) or the rich stimulus (during a rich component) for the remainder of the component, and the observing key was darkened and deactivated.

Table 1 shows the experimental conditions and the number of sessions in each. During the baseline condition, one or the other observing key was activated in every transition, and pecks on the active key could produce the lean stimulus or the rich stimulus. In the subsequent conditions, labeled A through D in Table 1, an observing key was activated only in selected transitions. This restricted the stimuli that could be produced and thereby allowed assessment of the reinforcing or punishing functions of the stimuli. In Conditions A and B, pecks on one observing key could produce the lean stimulus and the rich stimulus whereas pecks on the other observing key could produce only the rich stimulus. In Conditions $\mathrm{C}$ and $\mathrm{D}$, pecks on one observing key could produce the lean stimulus and the rich stimulus whereas pecks on the other key could only produce the lean stimulus. In addition, the consequences of pecking the left and right observing keys were exchanged across pairs of conditions. This reversal design separated the effects of the stimulus consequences of observing from any side biases.

The experimental conditions were arranged in two orders. The pigeons were randomly assigned to the orders, which are shown in Table 2.

Conditions lasted at least 20 sessions, except for replication conditions which lasted 10 sessions. All conditions lasted until the probabilities of left and right observing responses were judged stable by visual inspection, that is, until session-by-session plots of these two measures showed no increasing or decreasing trend across the last 5 sessions.

\section{Results}

The primary analyses measured the strength of pecking left and right observing keys in terms of probabilities and latencies. Pauses before pecking the food key also were measured. 
Table 1

The consequences of pecking the two observing keys in each condition.

\begin{tabular}{|c|c|c|c|c|c|c|c|c|c|c|c|c|c|c|}
\hline \multirow[b]{3}{*}{ Condition } & \multirow{2}{*}{\multicolumn{2}{|c|}{$\begin{array}{l}\text { Available Stimuli via } \\
\text { Each Observing Key }\end{array}$}} & \multirow{2}{*}{\multicolumn{4}{|c|}{$\begin{array}{l}\text { Transitions with Left } \\
\text { Observing Key Active }\end{array}$}} & \multirow{2}{*}{\multicolumn{4}{|c|}{$\begin{array}{l}\text { Transitions with Right } \\
\text { Observing Key Active }\end{array}$}} & \multicolumn{4}{|c|}{ Number of Sessions } \\
\hline & & & & & & & & & & & \multirow{2}{*}{$\begin{array}{l}\text { Bird } \\
6693\end{array}$} & \multirow{2}{*}{$\begin{array}{l}\text { Bird } \\
6994\end{array}$} & \multirow{2}{*}{$\begin{array}{l}\text { Bird } \\
6689\end{array}$} & \multirow{2}{*}{$\begin{array}{l}\text { Bird } \\
4266\end{array}$} \\
\hline & Left Key & Right Key & $L-L$ & $\mathrm{~L}-\mathrm{R}$ & R-L & $\mathrm{R}-\mathrm{R}$ & $\mathrm{L}-\mathrm{L}$ & L-R & R-L & $\mathrm{R}-\mathrm{R}$ & & & & \\
\hline Baseline & Lean, Rich & Lean, Rich & 5 & 5 & 5 & 5 & 5 & 5 & 5 & 5 & 23 & 20 & 20 & 22 \\
\hline$A$ & Lean, Rich & Rich & 5 & 5 & 5 & 5 & - & 5 & - & 5 & 20 & 20 & 20 & 20 \\
\hline B & Rich & Lean, Rich & - & 5 & - & 5 & 5 & 5 & 5 & 5 & 11 & 13 & 10 & 15 \\
\hline C & Lean & Lean, Rich & 5 & - & 5 & - & 5 & 5 & 5 & 5 & 21 & 23 & 39 & 22 \\
\hline D & Lean, Rich & Lean & 5 & 5 & 5 & 5 & 5 & - & 5 & - & 20 & 53 & 29 & 29 \\
\hline
\end{tabular}


Table 2

The order of experimental conditions for each bird.

\begin{tabular}{ccc}
\hline Condition & Birds 6994 \& 4266 & Birds 6693 \& 6689 \\
\hline Baseline & 1 & 1 \\
A & 2 & 4 \\
B & 3 & 5 \\
C & 4 & 2 \\
D & 5 & 3 \\
\hline
\end{tabular}


All analyses are based on data from the five stable sessions of each condition.

Figure 1 shows pausing on the food key during preliminary training as a function of the past component and stimulus correlated with the present component. Because no observing keys were active during this phase, pausing was measured only in the presence of the lean and rich stimuli. The results are medians and error bars signify interquartile ranges.

When the past component was lean (left side of Figure 1), pauses were brief with medians ranging from almost $0.5 \mathrm{~s}$ to $6 \mathrm{~s}$ for three birds and reaching almost $20 \mathrm{~s}$ for Bird 6689. Pauses were slightly longer when the stimulus correlated with the current component was lean compared to when it was rich. This difference was magnified when the past component was rich. Pauses were longest (medians ranged from nearly $23 \mathrm{~s}$ to $57 \mathrm{~s}$ ) when the current stimulus was lean but were short (1.5 s to $3 \mathrm{~s}$ ) when the current stimulus was rich. These results indicate that behavior was under the joint control of the past component and current stimuli.

Figure 2 illustrates the probabilities of pecking the left and right observing keys in each condition. Probabilities were calculated by dividing the number of observing responses by the number of times the response was made available. Note that in some conditions, an observing key was activated during every transition; in other conditions, a key was activated only in some transitions (see Table 1).

In the baseline condition (leftmost panel for each pigeon) when both keys could produce both the lean and rich stimuli, most birds pecked both keys at almost every opportunity. The exception, Bird 6693, rarely pecked the right key - evidently the result of position bias, as the consequences of the two keys were identical.

When one key produced both stimuli and the other produced only the rich stimulus (second and third panels in Figure 2), all of the birds pecked both keys at every opportunity. The 


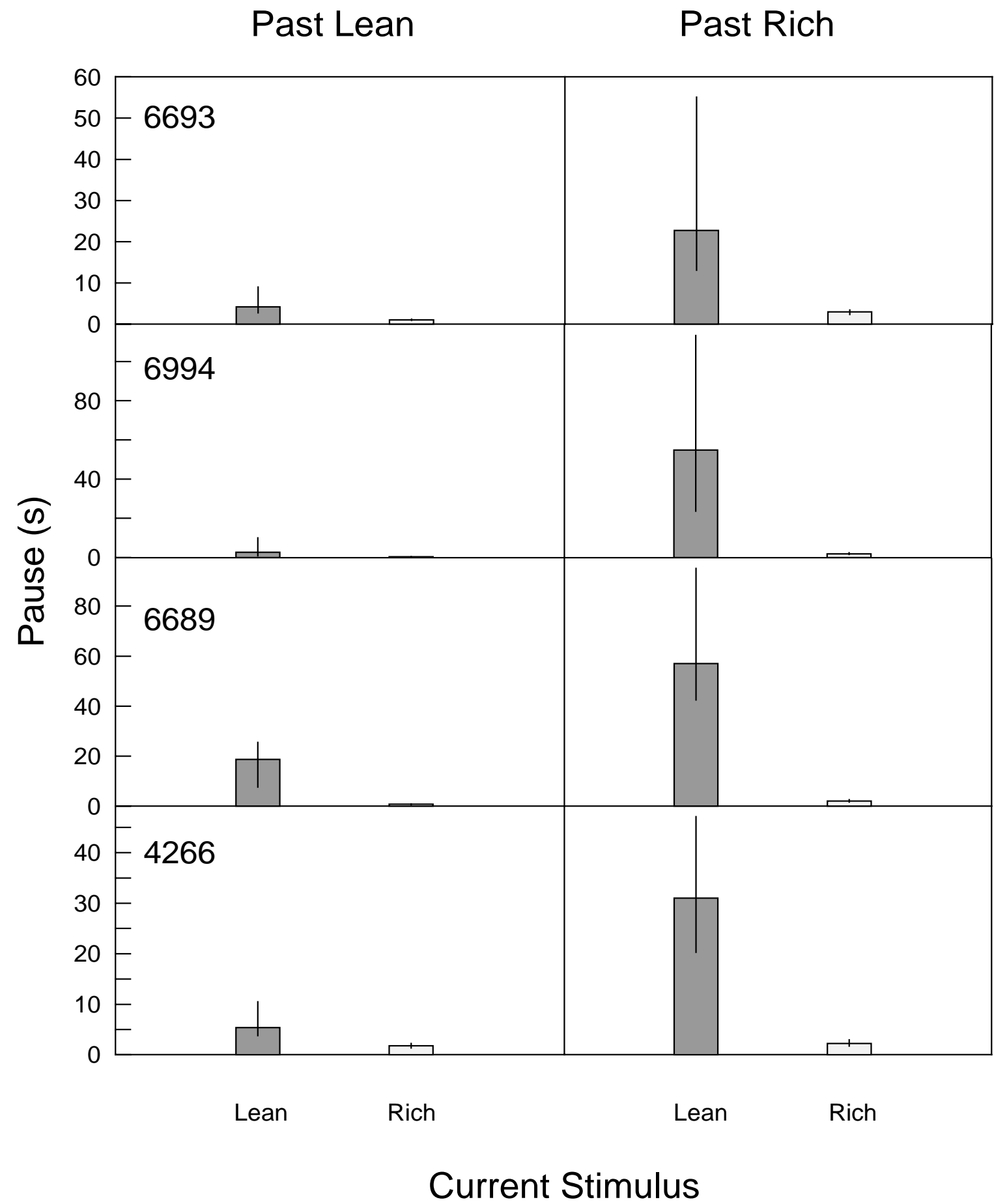

Figure 1. Pauses, in seconds, measured on the food key during preliminary training as a function of the past component and current stimulus. Data are medians. Error bars represent interquartile ranges. Note that the y-axis is scaled differently for each bird. 


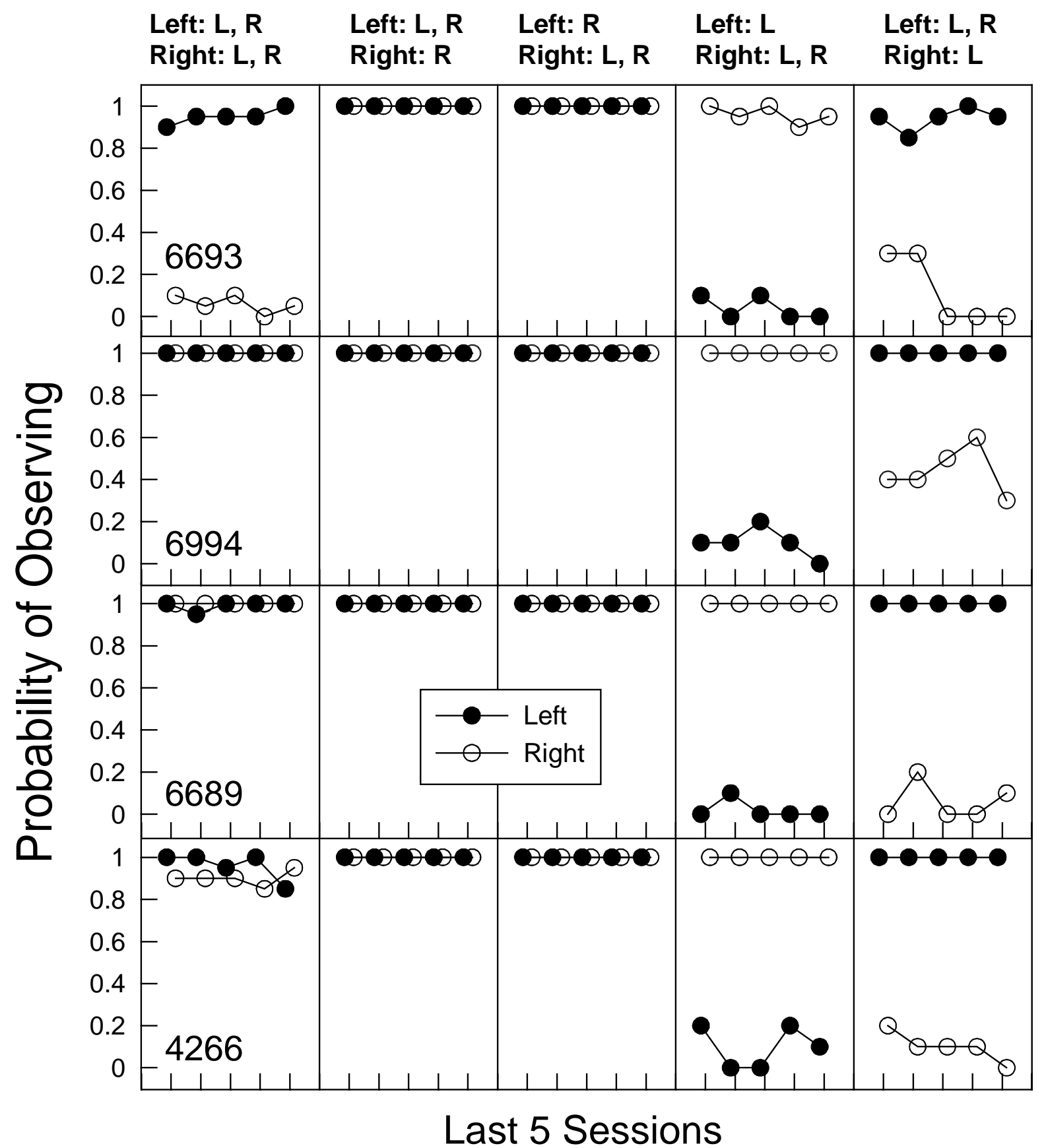

Figure 2. Probability of pecking the left and right observing keys. Conditions are defined by the stimuli produced by pecking each key: the lean stimulus (L) or the rich (R). Conditions were experienced in the order presented for Birds 6994 and 4266. Birds 6693 and 6689 experienced the conditions in the order shown in Table 2. 
rich stimulus functioned as a conditioned reinforcer, as the probability of pecking the key that produced only the rich stimulus was always 1.0. The function of the lean stimulus is less clear. If the lean stimulus were aversive, it would have suppressed observing. Hence, the probability of pecking would be lower on the key that produced both stimuli compared to the key that produced only the rich stimulus. As seen in Figure 2, however, the probability of observing was equally high (1.0) on both keys. This suggests one of two possibilities. First, perhaps the lean stimulus did not affect observing (was neutral) and the high probability of pecking the key that produced both stimuli was due to the reinforcing functions of the rich stimulus alone. Second, it may be that the lean stimulus, like the rich stimulus, functioned as a conditioned reinforcer, but a ceiling effect masked the effect of the lean stimulus.

Data from subsequent conditions clarify the behavioral functions of the lean stimulus. When one key produced both stimuli and the other produced only the lean stimulus (two rightmost panels), the birds pecked the key that produced both stimuli at almost every opportunity. They were much less likely to peck the key that produced only the lean stimulus. For three out of four birds, the probability of pecking the key that produced only the lean stimulus was 0.3 or less. The low probabilities of observing the lean stimulus indicate that the lean stimulus did not function as a conditioned reinforcer. Taken together, the results for all five conditions indicate that the rich stimulus reinforced observing and the lean stimulus neither reinforced nor punished observing.

To show the outcome of observing, Figure 3 displays the percentage of all ratios birds completed in the presence of the lean, mixed, and rich stimuli. Ratios were organized by the past component and percentages were calculated by dividing the number of ratios completed in the 


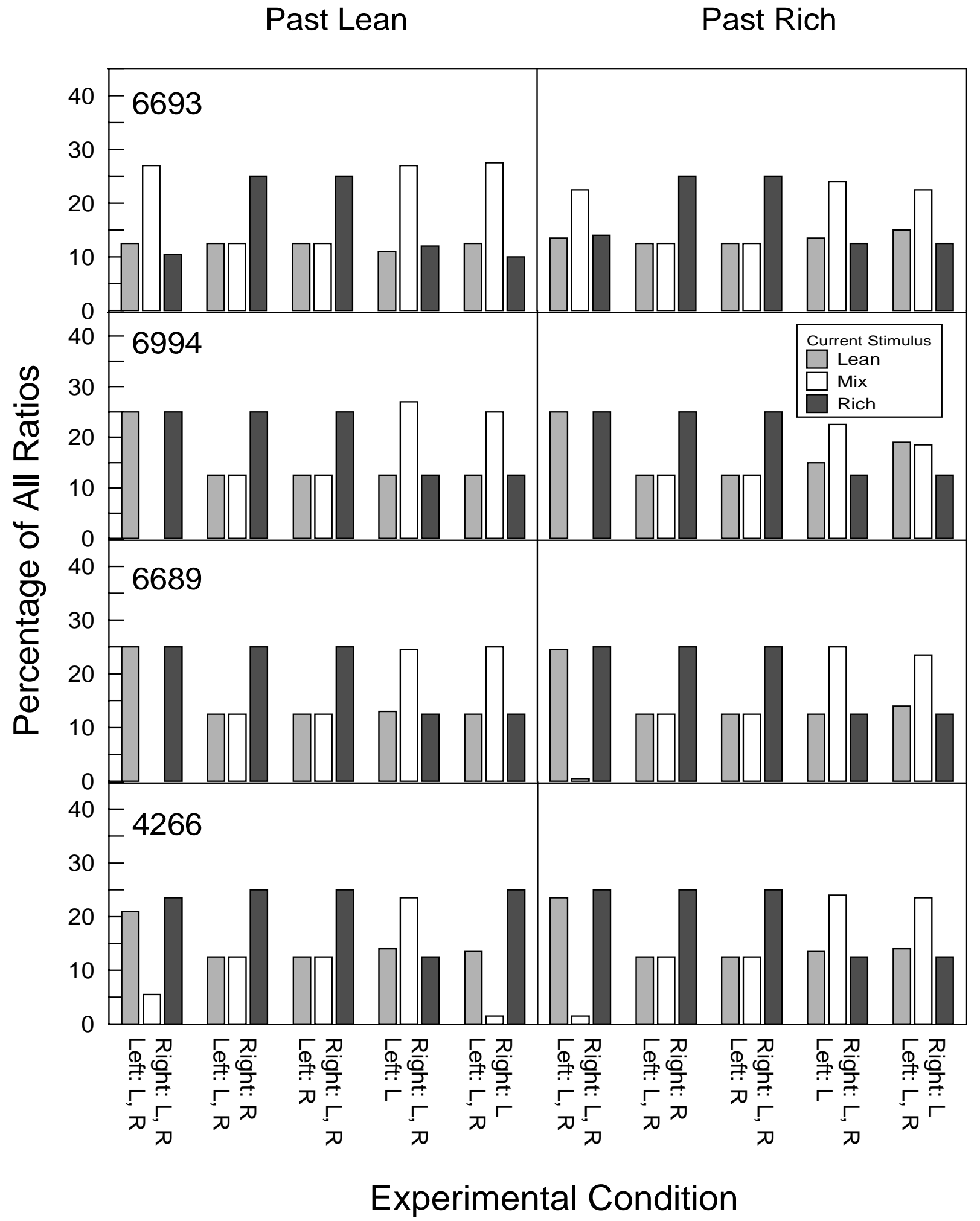

Figure 3. Percentage of all ratios completed in the presence of the lean, mixed, and rich stimuli as a function of the past component across all experimental conditions. 
presence of a particular stimulus by the total number of ratios completed within the experimental condition.

Regardless of the past component, pecks on either key produced both stimuli (first condition), birds observed the lean and rich stimuli equally often (approximately 25\% of all ratios were completed in the presence of the rich stimulus and the lean stimulus for Birds 6994, 6689, and 4266, and 11\% for bird 6693). Because three of the birds pecked both observing keys at every opportunity in this condition, none of their ratios were completed in the presence of the mixed stimulus. Bird 6693 was the exception as this bird rarely pecked the right key during this condition. As a result, some ratios were completed in the presence of the mixed stimulus. When the rich stimulus could be produced twice as often (second and third conditions), birds observed the rich stimulus more frequently. In these conditions, for all birds, approximately $25 \%$ of all ratios were completed in the presences of the rich stimulus. By contrast, when the lean stimulus could be produced twice as often (fourth and fifth conditions), more ratios were completed with the mixed stimulus (18 to $28 \%$ of all ratios for most birds).

Figure 4 shows the latency to peck the observing keys. Calculations only considered transitions in which an observing response was actually emitted; transitions absent of observing were disregarded. Medians are shown, and error bars represent interquartile ranges. In instances in which calculations were based on fewer than 20 latencies, numbers located above the bars indicate the total number of latencies used.

Overall, latencies tended to be brief with medians at or below 5 s. Exceptions occurred when the lean stimulus was the sole consequence of pecking one of the observing keys (fourth and fifth conditions). In some cases, the key that produced only the lean stimulus was never pecked. In the few instances when this key was pecked, however, latencies tended to be long, 


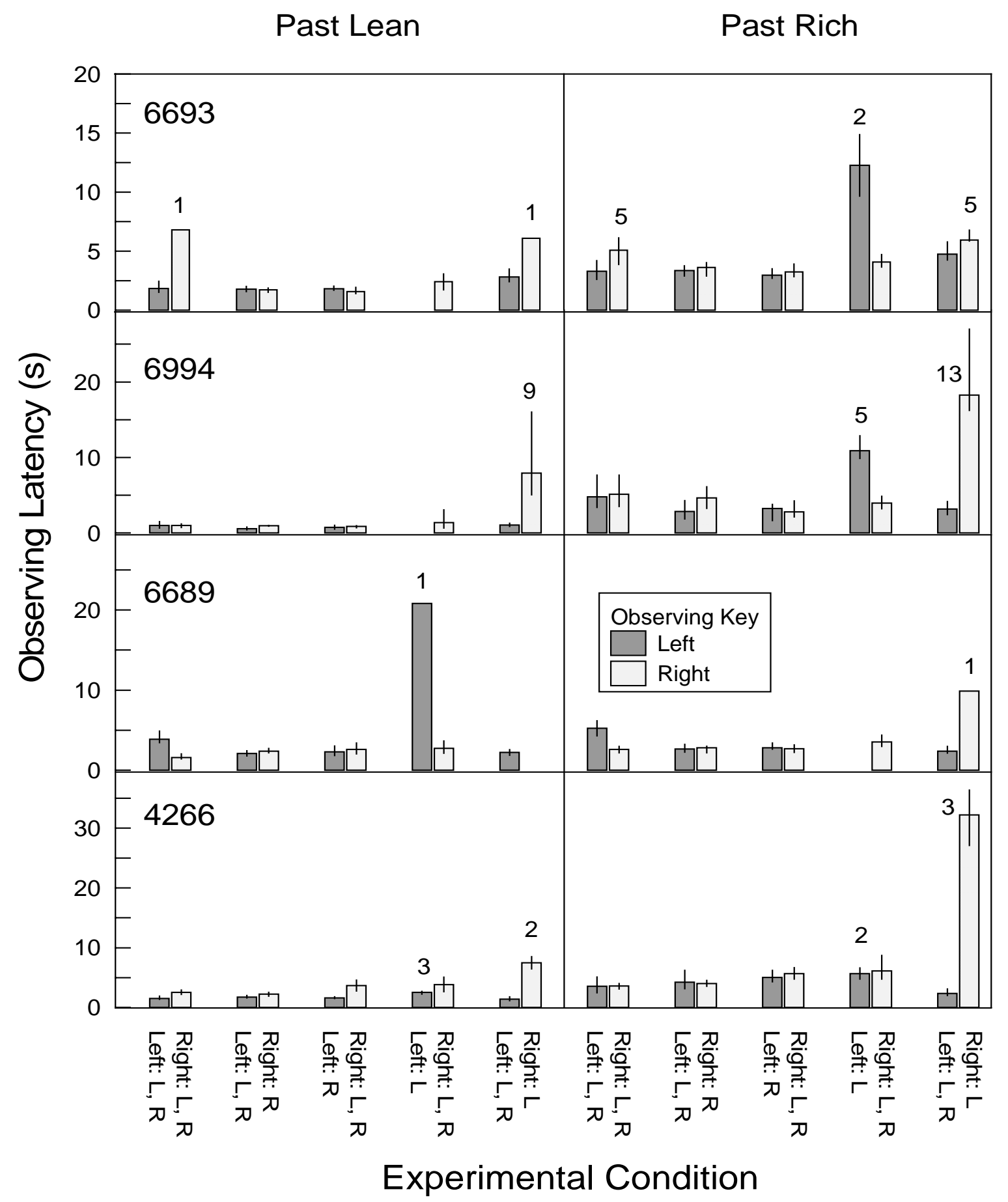

Figure 4. Latencies to peck the left and right observing keys according to the past component.

Data are medians; error bars represent interquartile ranges. Numbers above bars indicate the number of latencies used in calculating summary statistics. Y-axes are scaled differently for each bird. 
extending past $10 \mathrm{~s}$ at times. Latencies did not differ much as a function of the past component.

Of major interest is how local changes in the environment influenced the functions of the lean and rich stimuli. As issue, therefore, was the strength of observing when it could reveal the lean stimulus after a rich component versus after a lean component.

Table 3 compiles information about the observing procedure in the transitions after a rich component and after a lean component, and shows, for each condition, the probability that an observing response would produce the lean stimulus conditional on the past component. Consider, for example, the baseline condition. In ratios after a lean component, the left observing key was active 10 times and, if pecked each time, the lean stimulus would be produced 5 times, yielding a probability of .5. The table goes on to compile similar information for the ratios after a rich component and for the right key as well as the left. Comparing the strength of observing behavior in relation to the past component allowed assessment of the past component's effect on the reinforcing or aversive functions of the lean stimulus. Therefore, this comparison was conducted for the two conditions in which the probability that an observing response would produce the lean stimulus was zero, for the six conditions in which it was .5 (marked by an * in Table 3), and for the two conditions in which the probability was 1 (marked by ${ }^{* *}$ ). (No further analysis is needed to assess whether the functions of the rich stimulus were affected by the past component. Note for each condition in Table 3, the probability that an observing response would produce the rich stimulus conditional on the past component is the complement of the probability shown in the table.)

Figure 5 organizes the probabilities of pecking the observing keys according to the probability than an observing response will produce the lean stimulus. Consistent with data shown in Figure 2, regardless of the past component, birds tended to peck both observing keys at 
Table 3

Conditional probability that an observing response would produce the lean stimulus.

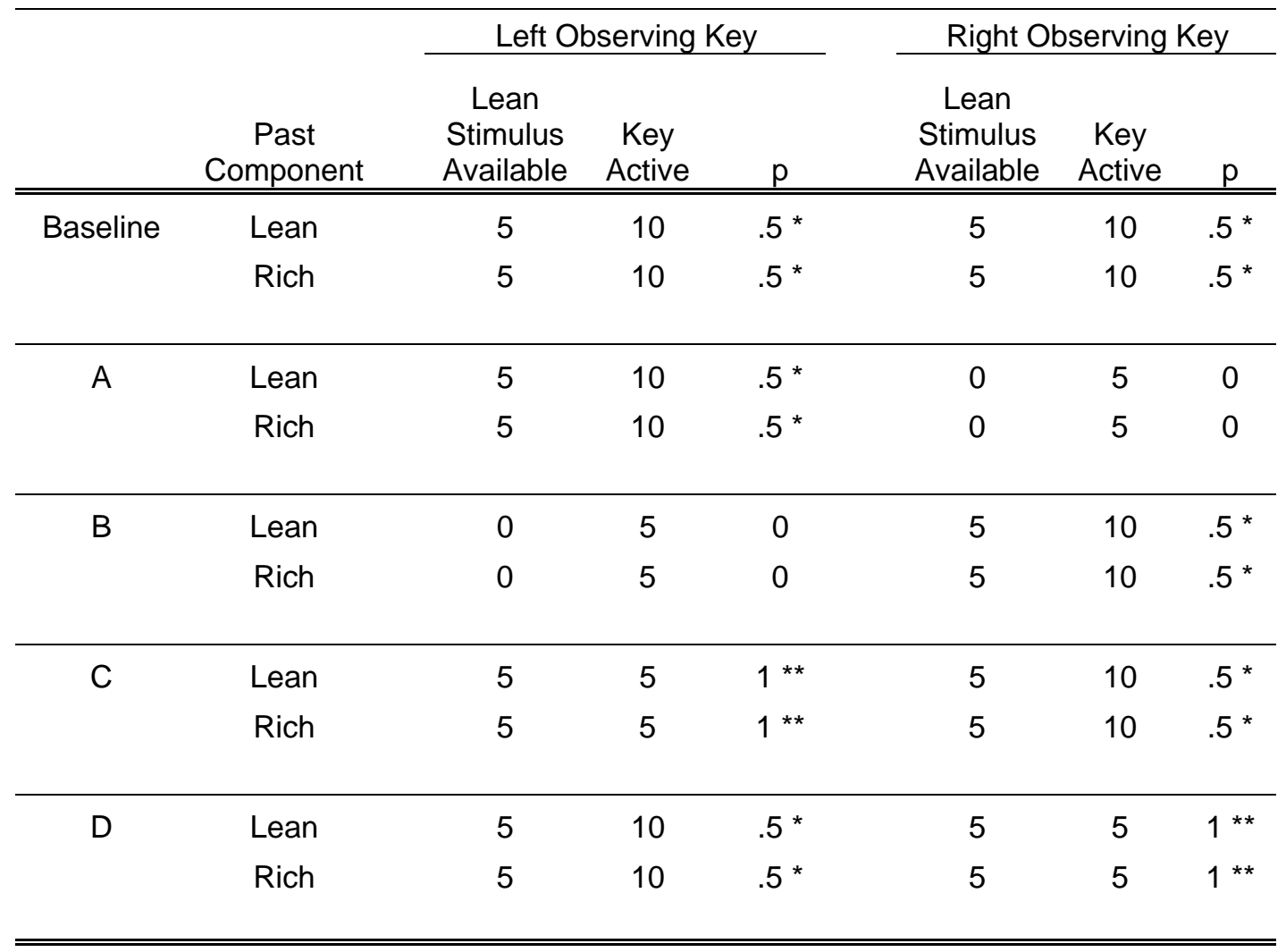




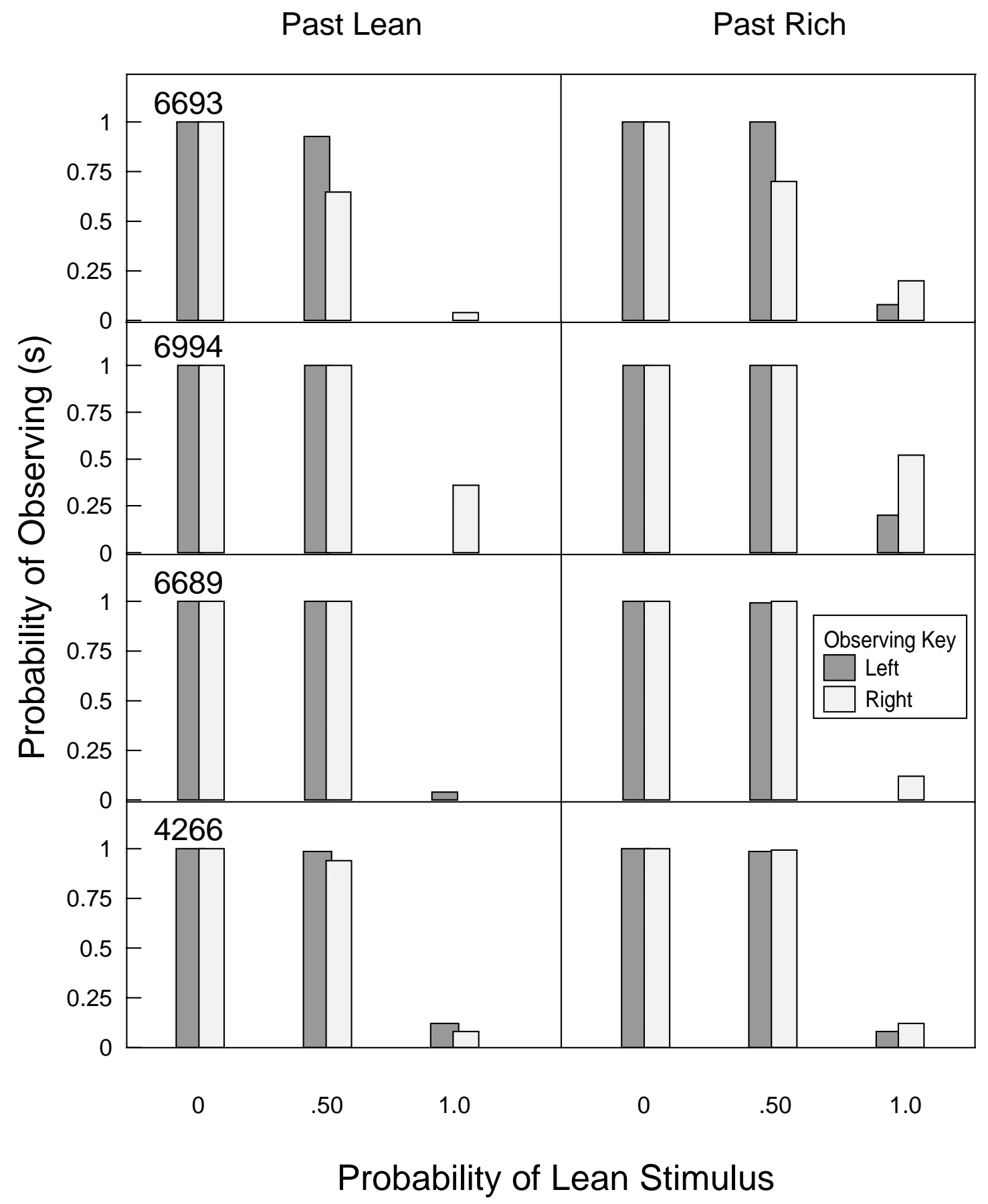

Figure 5. Probabilities of pecking the left and right observing keys as a function of the likelihood that the response will produce the lean stimulus $(0, .50,1)$ conditional on the past component. 
every opportunity when the probability of producing a lean stimulus was 0 and when it was .5 (when a rich stimulus would always be produced or when it would be produced half of the time). By contrast, when the likelihood of producing the lean stimulus was 1 (and the rich stimulus could never be produced), probabilities of observing were low.

Figure 6 presents a similar analysis but plots observing latencies instead of probabilities. Worth noting, however, is that the probability that an observing response will produce the rich stimulus can be determined from this information. Medians are shown; error bars represent interquartile ranges. In cases in which fewer than 20 latencies were used, numbers above the bars indicate the number of latencies considered.

Regardless of the past component, latencies were brief, lasting less than $5 \mathrm{~s}$, when a lean stimulus would never be produced and when it would be produced only half of the time (when a rich stimulus would always be produced or when it would be produced half of the time). When the lean stimulus was the sole consequence of observing latencies tended to be long with medians ranging from nearly $1.5 \mathrm{~s}$ to $32 \mathrm{~s}$. Note that during these conditions, only a small number of observing responses were made. The presence of just one bar, as opposed to two, indicates that observing responses were made on only one of the keys.

Figure 7 shows pausing on the food key as a function of the past component and current stimulus across conditions. Pausing was measured from the onset of the current stimulus to the time of the first peck on the food key. Data are medians; interquartile ranges are indicated by error bars.

When the past component was lean, pauses were brief. Medians ranged from $0.5 \mathrm{~s}$ to almost 20 s. Pauses were slightly longer when the current stimulus was lean. They also were slightly longer when the current stimulus was mixed in conditions where one observing key 


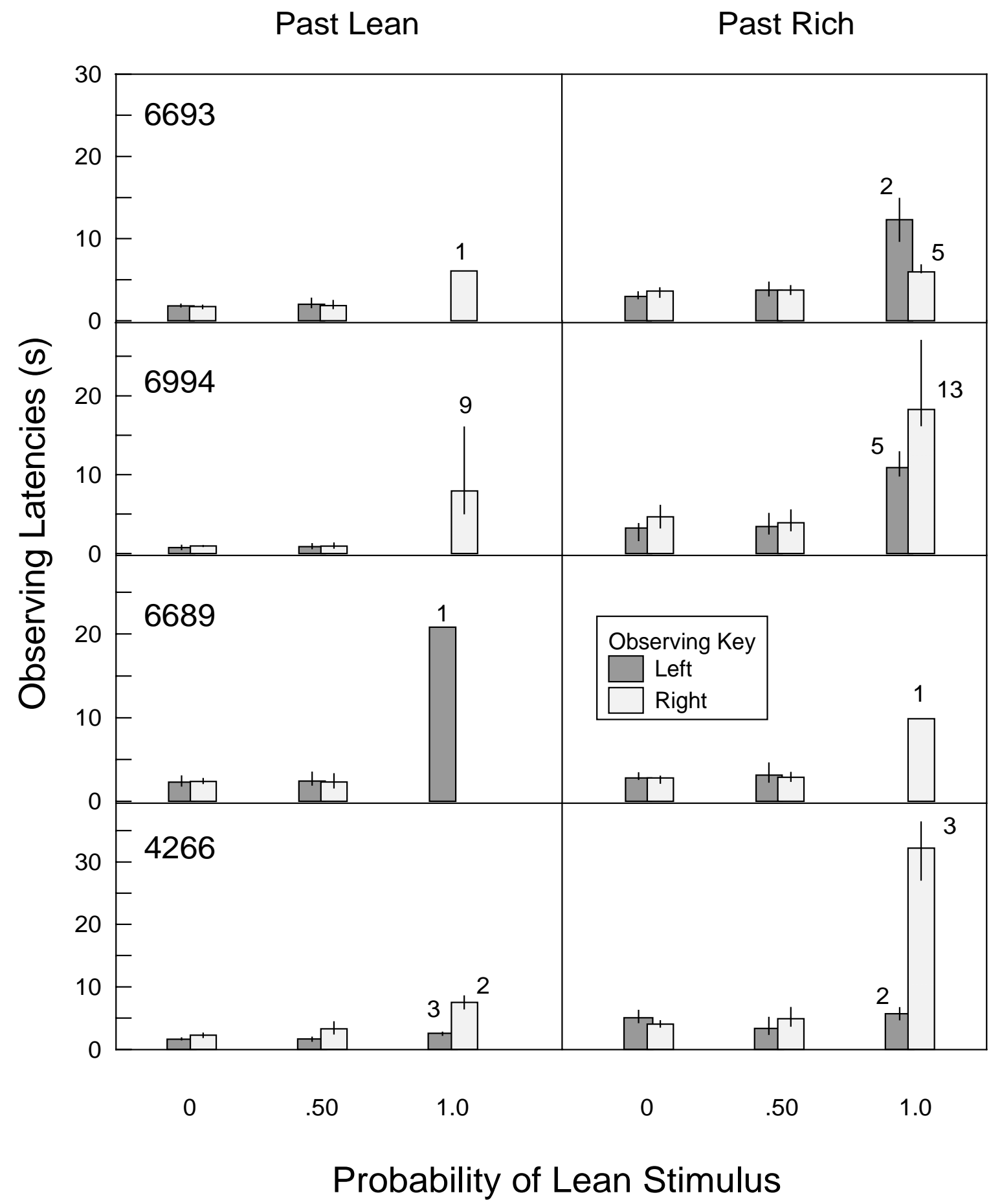

Figure 6. Latencies to peck the left and right observing keys as a function of the probability of producing a lean stimulus $(0, .50,1)$ conditional on the past component. Medians are shown. Interquartile ranges are indicted by error bars. Numbers positioned above the bars indicate the number of latencies used in calculating the results. Scaling of the y-axes varies across birds. 
Past Lean

Past Rich

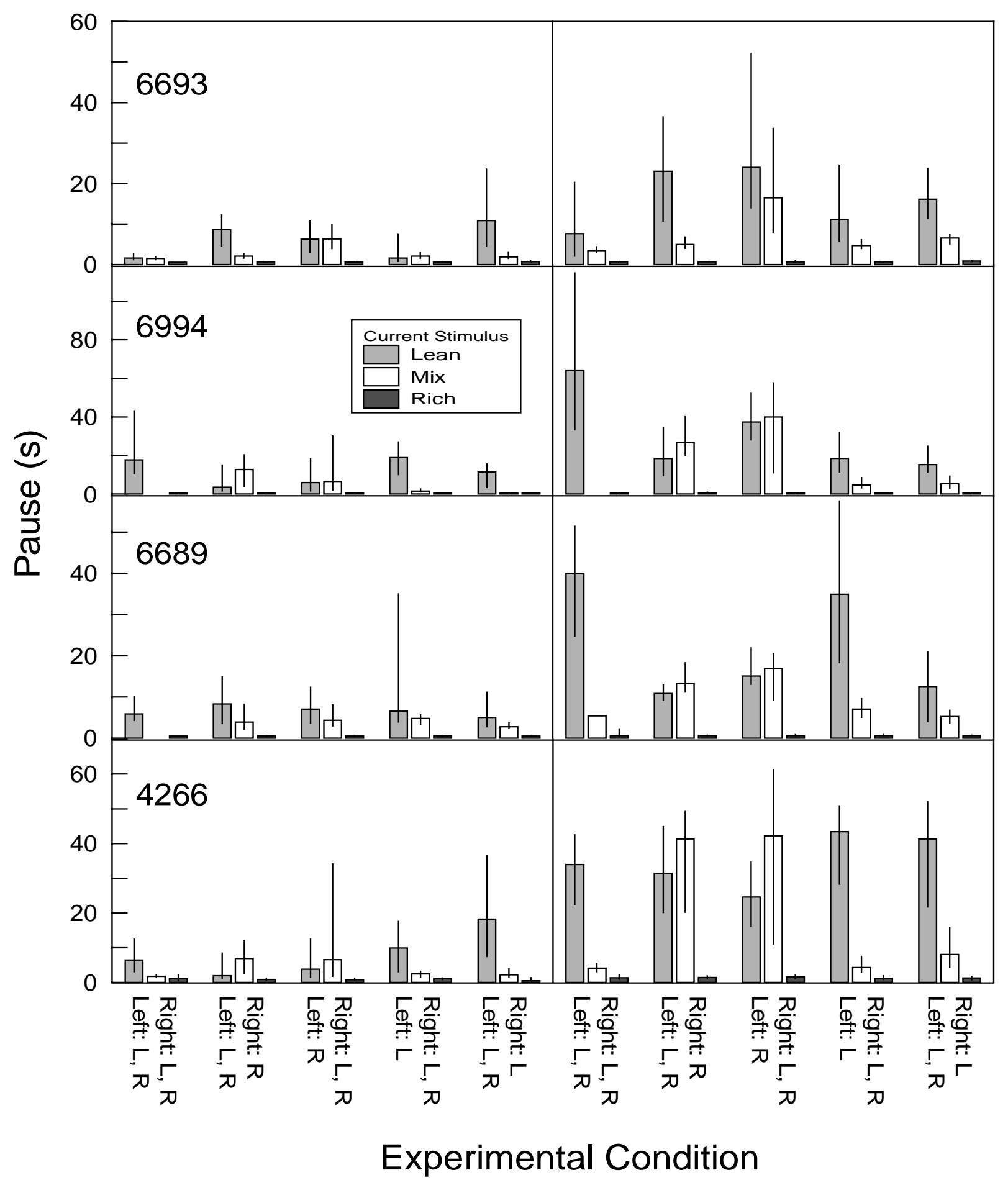

Figure 7. Pausing as a function of the past component (lean and rich) and current stimulus (lean, mixed, and rich). Data are medians, and error bars represent interquartile ranges. 
could only produce the rich stimulus. This is likely because, in these conditions, an observing key was only activated in some transitions. When the current component was lean, either the observing key that could produce both stimuli was activated or no observing key was activated and birds spent the component in the presence of the mixed stimulus. Hence, the absence of an active observing key (and the presence of the mixed stimulus) necessarily signaled that the current component was lean. In this sense, the mixed stimulus may have functioned similarly to the lean stimulus.

When the past component was rich, pauses were short ( $0.5 \mathrm{~s}$ to almost $20 \mathrm{~s})$ except when the stimulus correlated with the present component was lean. When the past component was rich and the current stimulus was lean, pausing was extended (medians ranged from approximately $10 \mathrm{~s}$ to $40 \mathrm{~s}$ ). This pattern is similar to that seen in Figure 1, where pausing was under the joint control of the past component and the stimulus correlated with the present component. In conditions where the rich stimulus was the sole consequence of pecking one of the observing keys, pauses also were long when the current stimulus was mixed. As noted previously, this likely is due to the similar functions of the lean and mixed stimuli in these conditions. The absence of an active observing key (and the presence of the mixed stimulus) necessarily signaled a lean component. As a result, pauses were long when the past component was rich and the current stimulus was mixed, indicating that in some cases, the mixed stimulus served as a discriminative stimulus for the lean component.

\section{Discussion}

The present study was designed to assess the functions of the rich and lean stimuli. Pigeons were trained on a multiple FR-100 FR-100 schedule with rich and lean components leading to large and small reinforcers. Pausing was brief in all transition types except in the 
transition from a rich component to a lean one, at which point pausing was extended. These pausing patterns were maintained in the experiment proper when the rich and lean stimuli were produced intermittently contingent upon an observing response. At issue were the reinforcing or aversive functions of the rich and lean stimuli and whether these functions would be modified by local changes in the environment. The functions of the rich and lean stimuli were assessed by comparing the strength of observing across conditions as indicated by the probabilities of pecking the observing keys.

The rich stimulus functioned as a conditioned reinforcer. Probabilities of observing were high when the rich stimulus could be produced and low when it could not be produced. Probabilities of observing did not vary as a function of the past component, indicating that the reinforcing strength of the rich stimulus was not influenced by local changes in the environment.

There was no evidence that the lean stimulus functioned as a conditioned punisher. If the lean stimulus had been aversive, it would have suppressed observing. Yet in conditions in which pecking one observing key produced both stimuli but pecking the other key produced only the rich stimulus, the probabilities of pecking were equally high on both keys. When pecking one observing key produced both stimuli but pecking the other key produced only the lean stimulus, the probabilities of pecking were relatively high on the key that produced both stimuli and low on the key that produced only the lean stimulus

There was no reliable evidence that the lean stimulus functioned as a conditioned reinforcer. If the lean stimulus had functioned as a conditioned reinforcer, probabilities of observing would have been higher when observing produced both stimuli rather than only the rich stimulus. Observing also would have been maintained when only the lean stimulus could be produced. As previously noted, however, probabilities of observing were equally high in 
conditions in which observing produced both stimuli or produced only the rich stimulus. Probabilities of observing were low when observing responses could produce only the lean stimulus. Taken together, these data indicate that the lean stimulus did not function as a conditioned reinforcer. Because the lean stimulus did not reliably maintain or suppress observing, the lean stimulus was neutral.

The conditioned reinforcing function of the rich stimulus is consistent with previous findings (e.g. Dinsmoor, Browne, \& Lawrence, 1972; Jwaideh \& Mulvaney, 1976; Mulvaney et al. 1974). Of greater interest, however, is that the lean stimulus did not function as a conditioned punisher. This inconsistency is particularly noteworthy given that previous findings indicate that the stimulus correlated with the leaner of two reinforcement schedules suppressing observing as well as maintains escape. For instance, in Jwaideh and Mulvaney’s (1976) experiment, observing response rates were low on the key that produced both stimuli but high on the key that produced only the rich stimulus, indicating that the lean stimulus functioned as a conditioned punisher. Metzger (1990) and Carlin (1997) also concluded that the lean stimulus functioned as a conditioned punisher as animals escaped from this stimulus when it was preceded by a rich component.

Given that the parameters used in the present experiment are identical to those shown by Metzger (1990) to generate escape, it is unlikely that the failure of the lean stimulus to function as a conditioned punisher can be attributed the parameters used. Also worth noting is that in the present experiment, pausing was under the joint control of both the past component and the stimulus correlated with the current component with extended pausing occurring in the rich-tolean transition.

The fact that the lean stimulus did not function as a conditioned punisher may be 
attributed to the way in which favorability was manipulated. In the present study, favorability was defined in terms of reinforcer magnitude. Rich components ended in a large reinforcer and lean components ended in a small one. According to some theories of conditioned reinforcement such as the delay-reduction hypothesis, however, the functions of rich and lean stimuli are predicted not on the basis of their correlation with reinforcers of a particular magnitude but on their correlation with a reduction in the delay to reinforcement. It is possible that the lean stimulus did not function as a conditioned punisher in the present experiment because delay to reinforcement was not manipulated. On the other hand, Fantino (1977) stated that the delayreduction hypothesis has broad implications for stimuli correlated with different reinforcer magnitudes, and this claim is supported in a study by Auge (1973).

If the failure of the lean stimulus to function as a conditioned punisher stems from manipulating favorability in terms of reinforcer magnitude rather than delay to reinforcement, additional experiments could examine the behavioral functions of the rich and lean stimuli using mixed FI FI schedules instead of ratio schedules. Components would then be equal in reinforcer magnitude but differ in the average delay to reinforcement. Mixed FR FR schedules could be used as well provided that the ratio sizes of the two components differed and the mean interreinforcement-intervals (IRIs) were measured, thereby ensuring that components also differed in the average delay to reinforcement.

It is interesting to note that while the lean stimulus did not function as a conditioned reinforcer, this stimulus did maintain some levels of observing. The low levels of observing maintained by the lean stimulus may have resulted from the stimulus change itself. Evidence for sensory reinforcement comes from an experiment by Case and Fantino (1981). They trained pigeons to respond on a mixed schedule with three FI-schedule components (FI-20 s, FI-120 s, 
and FI-180 s) that alternated in a pseudo-random fashion. In one condition, observing responses produced either the rich or lean stimuli. In another condition, however, observing responses either produced only the lean stimulus or produced another stimulus that was uncorrelated with the current component. Of interest was whether the uncorrelated stimulus would maintain observing. The uncorrelated stimulus did maintain observing whereas the lean stimulus did not. The maintenance of observing by the uncorrelated stimulus shows that some observing behavior may be accounted for by sensory reinforcement alone.

The overlapping consequences of pecking the observing key to produce the rich and the lean stimuli also may explain why the lean stimulus did not function as a conditioned punisher. For example, in Mulvaney et al.’s (1974) experiment, the immediate consequence of pecking an observing key was a 30-s display of the rich or lean stimulus on all three keys. By contrast, in the present experiment, regardless of whether an observing response would produce the rich or lean stimulus, the immediate consequence of pecking an observing key was the offset of the mixed stimulus on both the observing key and the food key (the food key was then relit with the appropriate discriminative stimulus). In this sense, the immediate consequences of pecking to observe the rich and lean stimuli overlapped. The overlap in the immediate consequences of pecking to produce the rich stimulus and the lean stimulus may reduce the sensitivity of the present procedure in assessing the functions of the rich and lean stimuli.

Future research should attempt to replicate the present study's findings when the immediate consequences of making an observing response do not overlap across the rich and lean stimuli. For example, rather than turning off the mixed stimulus on the observing key and replacing the mixed stimulus on the food key with the rich or lean stimulus, an observing response could replace both the mixed stimulus on the observing key and that on the food key 
with a stimulus correlated with the current component. The amount of overlap in the immediate consequences of producing the rich and lean stimuli thereby would be reduced, allowing for a more sensitive means of assessing the functions of the rich and lean stimuli. 


\section{References}

Appel, J. B. (1963). Aversive aspects of a schedule of positive reinforcement. Journal of the Experimental Analysis of Behavior, 6, 423-428.

Ator, N.A. (1980). Mirror pecking and timeout under a multiple fixed-ratio schedule of food delivery. Journal of the Experimental Analysis of Behavior, 6, 423-428.

Auge, R. J. (1973). Effects of stimulus duration on observing behavior maintained by differential reinforcement magnitude. Journal of the Experimental Analysis of Behavior, 20, 429-438.

Auge, R. J. (1974). Context, observing behavior, and conditioned reinforcement. Journal of the Experimental Analysis of Behavior, 22, 525-533.

Azrin, N. H. (1961). Time-out from positive reinforcement. Science, 34, 382-383.

Bejarno, F., Williams, D. C., \& Perone, M. (2003). Pausing on multiple schedules: Toward a laboratory model of escape-motivated behavior. Experimental Analysis of Human Behavior Bulletin, 21, 18-20.

Blanchard, R. (1975). The effect of S- on observing behavior. Learning and Motivation, 6, 1-10.

Brown, T. G., \& Flory, R. K., (1972). Schedule induced escape from fixed-interval reinforcement. Journal of the Experimental Analysis of Behavior, 17, 395-403.

Carlin, L. (1997). Pausing and escape on fixed-interval schedules of food reinforcement: Effects of interval length and reinforcer magnitude. Unpublished master's thesis, West Virginia University.

Case, D. A., \& Fantino, E. (1981). The delay-reduction hypothesis of conditioned reinforcement and punishment: Observing behavior. Journal of the Experimental Analysis of Behavior, 35, 93-108. 
Cohen, P. S., \& Campagnoni, F. R. (1989). The nature and determinants of spatial retreat in the pigeon between periodic grain presentations. Animal Learning and Behavior, 17, 39-48.

Courtney, K. (1994). Pausing on fixed-ratio and fixed-interval schedules of food reinforcement: Tests of the Escape Hypothesis. Unpublished doctoral dissertation, West Virginia University.

Dardano, J. F. (1973). Self-imposed timeouts under increasing response requirements. Journal of the Experimental Analysis of Behavior, 19, 269-287.

Dinsmoor, J. A., Browne, M. P., \& Lawrence, C. E., (1972). A test of the negative discriminative stimulus as a reinforcer of observing. . Journal of the Experimental Analysis of Behavior, 18, 79-85.

Fantino, E. (1977). Conditioned reinforcement: Choice and information. In W. K. Honig \& J. E. R. Staddon (Eds.), Handbook of operant behavior (pp. 313-339). Englewood Cliffs, NJ; Prentice-Hall.

Jwaideh, A., R. \& Mulvaney, D. E. (1976). Punishment of observing by a stimulus associated with the lower of two reinforcement frequencies. Learning and Motivation, 7, 211-222.

Kendall, S. B., \& Gibson, D. A. (1965). Effect of discriminative stimulus removal on observing behavior. The Psychological Record, 15, 545-551.

Metzger, B. (1990). Escape from fixed-ratio schedules as a function of reinforcer magnitude. Unpublished master’s thesis, West Virginia University.

Mulvaney, D. E., Dinsmoor, J. A., Jwaideh, A. R., \& Hughes, L. H. (1974). Punishment of observing by the negative discriminative stimulus. Journal of the Experimental Analysis of Behavior, 21, 37-44. 
O'Daly, M., Meyer, S., \& Fantino, E. (2005). Value of conditioned reinforcers as a function of temporal context. Learning and Motivation, 36, 42-59.

Perone, M. (2003). Negative effects of positive reinforcement. The Behavior Analyst, 26, 1-14.

Perone, M. \& Baron, A. (1980). Reinforcement of human observing behavior by a stimulus correlated with extinction or increased effort. Journal of the Experimental Analysis of Behavior, 34, 239-160.

Perone, M., \& Courtney, K. (1992). Fixed-ratio pausing: Joint effects of past reinforcer magnitude and stimuli correlated with upcoming magnitude. Journal of the Experimental Analysis of Behavior, 57, 33-46.

Perone, M. \& Kaminski, B. J. (1992). Conditioned reinforcement of human observing behavior by descriptive and arbitrary verbal stimuli. Journal of the Experimental Analysis of Behavior, 58, 557-575.

Preston, R. A., \& Fantino, E. (1991). Conditioned reinforcement value and choice. Journal of the Experimental Analysis of Behavior, 55, 155-175.

Wade-Galuska, T., Perone, M., \& Wirth, O. (2004). Effects of past and upcoming response-force requirements on fixed-ratio pausing. Behavioral Processes, 68, 91-95.

Williams, W. A., \& Fantino, E. (1994). Delay-reduction and optimal foraging; Variable-ratio search in a foraging analogue. Journal of the Experimental Analysis of Behavior, 61, 465-477.

Wyckoff, L. B., (1952). The role of observing responses in discrimination learning. Psychological Review, 59, 431-442. 